contamination. Wipes were analysed by ultra-performance liquid chromatography tandem-mass spectrometry for 10 ANPs. Limits of detection (LOD) varied by a factor of 10 according to sampled area and ANP. Descriptive statistics are presented here.

Result Overall, 11 of the 16 types (68.8\%) of sampled surfaces were above the LOD for at least one ANP; gemcitabine and cyclophosphamide were most often identified $(30.6 \%$ and $29.8 \%$ of samples respectively), followed by 5 -fluorouracil and irinotecan (both 15.6\% above LOD). Highest levels were all found in the outpatient clinic: 5-fluorouracil $\left(49 \mathrm{ng} / \mathrm{cm}^{2}\right)$ and irinotecan $\left(3.6 \mathrm{ng} / \mathrm{cm}^{2}\right)$, toilet floor; cyclophosphamide (19.6 $\left.\mathrm{ng} / \mathrm{cm}^{2}\right)$, IV pump; gemcitabine $\left(4.97 \mathrm{ng} / \mathrm{cm}^{2}\right)$, cytotoxic waste bin cover. Hand wipes were above the LOD for five of seven nurses, one of seven pharmacy personnel and none of three sampled HS workers.

Discussion A notable proportion of surfaces showed measurable levels of ANPs, with highest concentrations on surfaces cleaned by HS personnel. Prevention programs should integrate regular monitoring of hospital surfaces in order to evaluate environmental contamination and sharing monitoring results with all concerned personnel, together with appropriate training, in order to raise their awareness of ANP exposures.

\section{APPRAISAL OF WORK ABILITY IN RELATION TO JOB- SPECIFIC HEALTH REQUIREMENTS IN AMBULANCE WORKERS}

1,2 van Schaaijk, ${ }^{1,2}$ JS Boschman, ${ }^{1,2} \mathrm{MHW}$ Frings-Dresen, ${ }^{1,2} \mathrm{JK}$ Sluiter. ${ }^{1}$ Coronel Institute of Occupational Health, Academic Medical Centre, Amsterdam, The Netherlands; ${ }^{2}$ Amsterdam Public Health research institute, Amsterdam, The Netherlands

\subsection{6/oemed-2018-ICOHabstracts.924}

Introduction To gain insight into which job-specific health requirements relate to self-estimated work ability, the following two research questions were formulated: Which job-specific health requirements are associated with the appraisal of work ability in ambulance drivers and paramedics? How are appraisals of physical and mental work ability associated with the appraisal of overall work ability in ambulance drivers and paramedics?

Methods Workers Health Surveillance cross-sectional data of 506 ambulance workers (236 drivers and 270 paramedics) were used. The outcomes for specific job requirements were divided into six categories; 'having raised alertness and judgment ability', 'dealing with emotional peak load', 'to perceive and communicate', 'job-specific physical abilities', 'skin complaints' and 'respiratory complaints'. Work ability was appraised as overall, physical and mental/emotional. Multiple linear stepwise regression analyses were used to model the associations.

Result Outcomes in 'raised alertness and judgment ability' $(\mathrm{R} 2=0.09)$, ‘job-specific physical abilities' $(\mathrm{R} 2=0.10)$ and 'emotional peak load' $(\mathrm{R} 2=0.07)$ significantly explained appraised overall, physical and mental/emotional work ability $(\mathrm{p}<0.01)$. Physical and mental/emotional work ability together explained $48 \%$ of the variance in overall work ability. The explained variance by physical and mental/emotional work ability was almost $4 \%$ higher in drivers than in paramedics.

Discussion The appraisal of overall work ability was significantly explained by outcomes in 'raised alertness and judgment ability' and 'emotional peak load.' Physical work ability was significantly explained by 'job-specific physical abilities' and 'raised alertness and judgment ability' outcomes, while 'emotional peak load' and 'raised alertness and judgment ability' outcomes significantly explained mental/emotional work ability. Physical and mental/emotional work ability explain the same proportion of variance in overall work ability.

\section{HEALTH CARE WORKERS' SAFE PATIENT HANDLING AND MOVEMENT KNOWLEDGE: A CROSS-SECTIONAL STUDY IN A DEVELOPING COUNTRY}

João Marcos Bernardes*, Adriano Dias. Botucatu Medical School/UNESP, Botucatu, Brazil

\subsection{6/oemed-2018-ICOHabstracts.925}

Introduction Healthcare workers worldwide present a high prevalence and incidence of low back pain due to manual patient handling tasks. Although education encourage the use of safe patient handling procedures, there is a lack of research about safe patient handling knowledge in developing countries. Therefore, the purpose of this study was to examine both levels of knowledge and factors associated with a good knowledge score among healthcare workers of a developing country. Methods This was a cross-sectional study with 292 healthcare workers from the University Hospital of Botucatu Medical School. A knowledge score was generated based on participant responses to a structured questionnaire, with a score of $70 \%$ or higher indicating good knowledge. Frequency statistics and logistic regression were conducted to analyse the data.

Result The majority of participants did not achieve a good level of knowledge (81,5\%). Only 54,1\% were aware of the high risk presented by patient-handling tasks. Most participants $(84,8 \%)$ were not knowledgeable of the recommended maximum weight limit for use in patient-handling tasks, $62,3 \%$ and $53,4 \%$ answered that relying on proper body mechanics and that the use of back belts are effective prevention methods, respectively. The knowledge gap was most prominent in the domain of safe patient handling, only $2,4 \%$ of participants answered correctly all questions regarding this topic. Regarding the associated factors towards a good level of knowledge, the only significant relationship in univariate as well as multiple logistic analysis was level of education, being less educated - elementary or high school education - was a significant predictor of lower levels of knowledge $(\mathrm{OR}=4.776$, 95\% CI: 1.056 to 21.600$)$.

Discussion A substantial knowledge deficit was identified among healthcare workers in our study. Policies and education campaigns to increase knowledge and improve preventive practices should be developed.

\section{PREVALENCE OF THYROID DISEASES IN AN OCCUPATIONALLY RADIATION EXPOSED GROUP: A CROSS-SECTIONAL STUDY IN A UNIVERSITY HOSPITAL OF SOUTHERN ITALY}

${ }^{1} \mathrm{~L}$ Vimercati*, ${ }^{1} \mathrm{P}$ Lovreglio, 'L De Maria, ${ }^{2} \mathrm{~V}$ Luisi, , $\mathrm{GM}$ Ferri, ${ }^{3} \mathrm{~F}$ Cuccaro, ${ }^{1} \mathrm{M}$ Quarato, ${ }^{1} \mathrm{~L}$ Soleo. ${ }^{1}$ Interdisciplinary Department of Medicine, University of Bari Medical School, Bari, Italy; ${ }^{2}$ Occupational Health Unit, 'Azienda Ospedaliero-Universitaria Consorziale Policlinico di Bari', Bari, Italy; ${ }^{3}$ Health Local Unit of Barletta-Andria-Trani, Barletta, Italy

\subsection{6/oemed-2018-ICOHabstracts.926}

Introduction Thyroid diseases occur more frequently in people exposed to ionising radiation (IR) for therapeutic purposes 